\title{
DEVELOPMENT OF A COMPUTERIZED DATA BASE OF PERMITTED WASTEWATER DISCHARGES IN NEW JERSEY
}

By Keith W. Robinson, Curtis V. Price, and Richard A. Smith

U.S. GEOLOGICAL SURVEY

Open-File Report 95-152

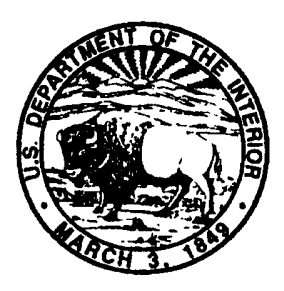

West Trenton, New Jersey 


\title{
U.S. DEPARTMENT OF THE INTERIOR BRUCE BABBITT, Secretary
}

\author{
U.S. GEOLOGICAL SURVEY \\ Gordon P. Eaton, Director
}

For additional information write to:

District Chief

U.S Geological Survey Mountain View Office Park

810 Bear Tavern Road, Suite 206

West Trenton, NJ 08628
Copies of this report can be purchased from:

U.S. Geological Survey

Earth Science Information Center

Open-File Reports Section

Box 25286, MS 517

Denver Federal Center

Denver, CO 80225 


\section{CONTENTS}

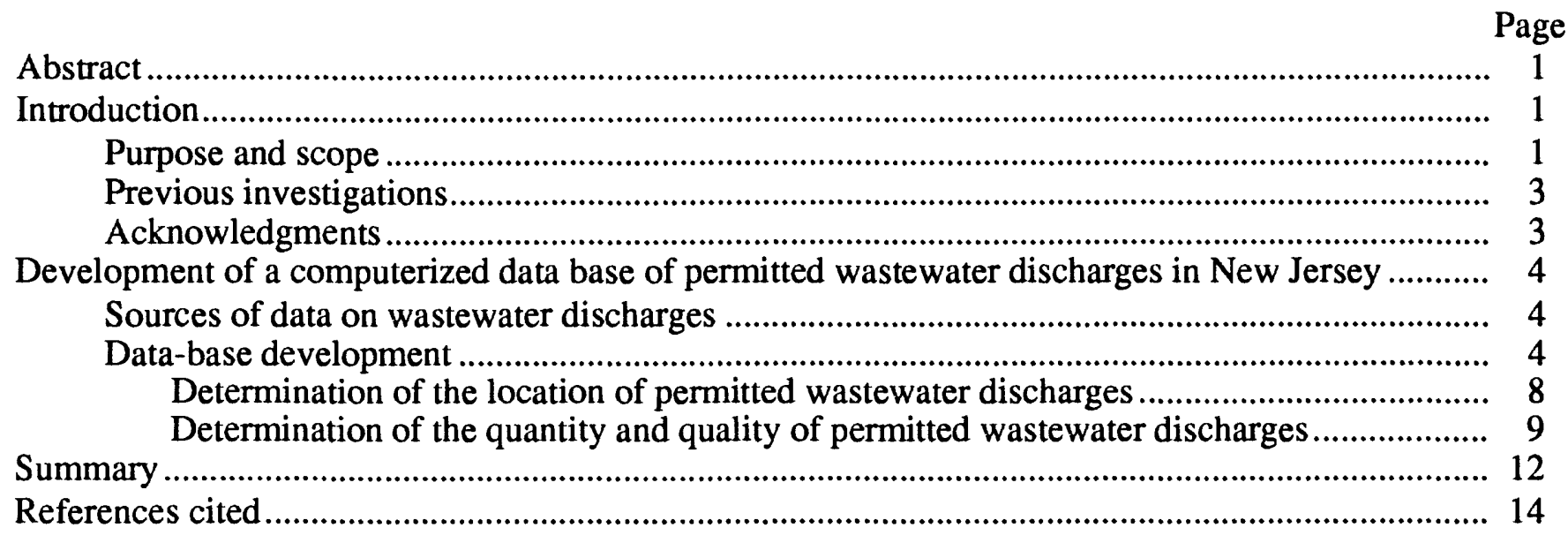

\section{FIGURES}

Figure 1. Map showing location of the study area

2.-3. Flow charts showing:

2. Methods used to determine location of permitted wastewater discharges

3. Methods used to determine quantity and quality of permitted wastewater discharges

4. Map showing locations of the 696 permitted wastewater discharges to surface waters in the study area

\section{TABLES}

Table 1. Information collected and stored in the data base of permitted wastewater discharges 


\section{CONVERSION FACTORS}

\begin{tabular}{rcl}
\multicolumn{1}{c}{ Multiply } & By & To Obtain \\
inch (in) & 25.4 & millimeter \\
foot (ft.) & 0.3048 & meter \\
mile (mi) & 1.609 & kilometer \\
square mile (mi $\left.{ }^{2}\right)$ & 2.590 & square kilometer \\
million gallons per day (Mgal/d) & 0.04381 & cubic meter per second
\end{tabular}




\title{
DEVELOPMENT OF A COMPUTERIZED DATA BASE OF PERMITTED WASTEWATER DISCHARGES IN NEW JERSEY
}

\author{
By Keith W. Robinson, Curtis V. Price, and Richard A. Smith
}

\begin{abstract}
This report describes the development of a computerized data base containing information on the locations of 696 permitted wastewater discharges in New Jersey; the quantity and quality of the wastewater also are described. The data base was needed for use in a regional surface-water-quality model. The Permit Compliance System data base, a national data base of permitted wastewater discharges maintained by the U.S. Environmental Protection Agency, provided locational information for 51 percent of all permitted discharges in New Jersey and information on either the quantity or quality of the wastewaters discharged for 74 percent of the 696 permitted discharges. Additional sources of information were needed to complete the data base. Because of errors in the Permit Compliance System data, quality-control measures were incorporated into the development of the data base to ensure that the information contained in the data base was accurate and complete.
\end{abstract}

\section{INTRODUCTION}

The effects of municipal and industrial wastewater discharges on surface-water quality are well documented and are a major reason for the focus of national water-pollution-control activities on these sources of water contamination since the early 1970's (Association of State and Interstate Water Pollution Control Administrators, 1984; U.S. Environmental Protection Agency, 1987). Because wastewater discharges affect water quality, studies that attempt to analyze and model water-quality conditions in specific waterways must often incorporate information on the presence, location, type, amount, and quality of wastewaters discharged. This is especially true in New Jersey where the quality of many surface waters is significantly affected by the approximately 1,100 permitted wastewater discharges in the State (New Jersey Department of Environmental Protection, 1990).

An effort to statistically model surface-water-quality conditions in New Jersey is described by Smith and others (1989). They proposed the development of logistic and ordinary-least-squares multiple regression models to predict water quality in fresh, nontidal surface waters in New Jersey (fig. 1). Predicators of water quality used in the regression models included data on land-use types, population, and wastewater discharges. New Jersey was selected as the study area for model development because it is small, contains a variety of land-use types, has an extensive surface-water-quality monitoring program, and is considered to have a fairly complete data set on sources of water-quality contamination. The data set includes information on the presence, location, type, amount, and quality of wastewaters discharged.

\section{Purpose and Scope}

The purpose of this report is to describe the results of a study conducted during 1989-91 to develop a computerized data base for use with the computer model discussed by Smith and others (1989). The data base contains information on permitted wastewater discharges to surface waters in those areas of New Jersey to be modeled. Data on permitted wastewater discharges needed for the model included the location of all such discharges, the type of wastewater discharged, and the quantity and quality of the wastewaters. Sources of data, procedures developed to ensure the completeness and accuracy of the data, and results of the various processes employed are discussed. 


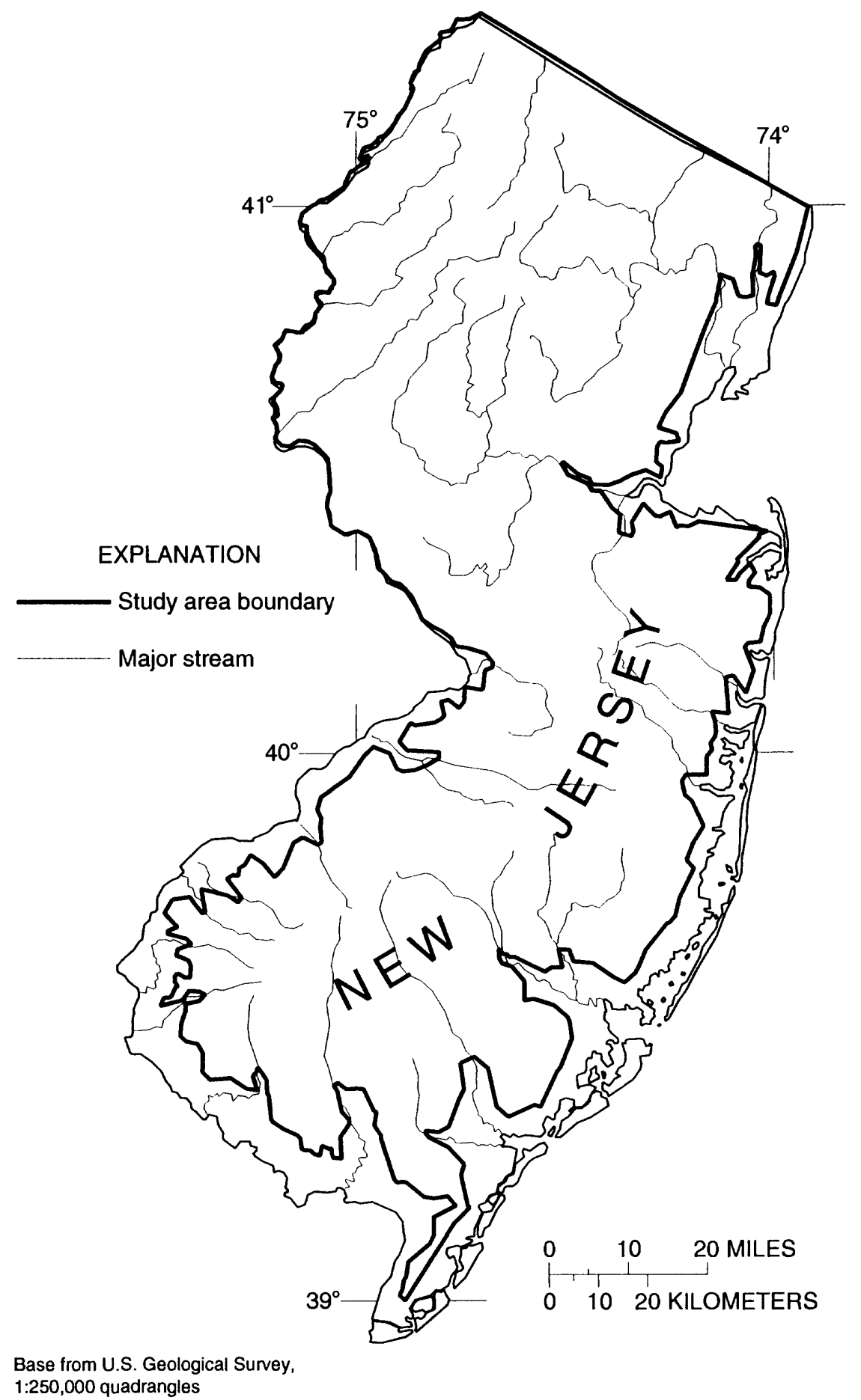

Figure 1. Location of study area. 


\section{Previous Investigations}

A limited amount of work has been presented in the literature that describes the development of data bases for a large number of permitted wastewater discharges. Luken and others (1976) prepared a national inventory of residuals generated from point and nonpoint sources and estimated how residuals might change as a result of the Federal Clean Water Act of 1972. The amount of biological oxygen demand and total suspended solids released by 24,200 municipal wastewater treatment facilities was estimated from U.S. Environmental Protection Agency's (USEPA) 1974 Needs Survey, the number of people and industries served by the facility, and industry standards of typical municipal wastewater influent. Estimates of industrial wastewaters were based on a combination of plantspecific data and waste-generation coefficients by industry type. Luken and others (1976) stated that the information gathered was the best at the time for a national data base, but that the accuracy of the data was difficult to determine.

Gianessi and Peskin (1984) compiled a data base of more than 32,000 point sources and their associated wastewater flows and loads as part of an effort to estimate national pollutant loads from point and nonpoint sources. To complete their data base, Gianessi and Peskin used USEPA's Industrial Facilities Discharge (IFD) data base, USEPA Needs Survey reports, numerous local publications, and contacts with state and local agency personnel. Gianessi and Peskin were able to collect information on wastewater quantity and quality from existing USEPA data bases for 52 percent of the point sources in their inventory.

The availability and suitability of existing information on permitted municipal wastewater discharge facilities for use in a regional water-quality study is described by Zogorski and others (1990). In attempting to characterize municipal wastewater discharge impacts on stream water quality in the Upper Illinois River Basin, they found that available information describing the quantity and quality of wastewater discharges was of limited use because few water-quality constituents in the wastewaters were routinely analyzed for, the frequency of effluent sampling at some facilities was insufficient, and the quality of reported flow rates could not be assured. They concluded that existing state and federal data bases of wastewater discharges generally lacked information needed in water-quality assessment studies.

The National Oceanic and Atmospheric Administration developed a number of permitted wastewater discharge data bases as part of the National Coastal Pollutant Discharge Inventory Program (NCPDI) (National Oceanic and Atmospheric Administration, 1993a and 1993b). The NCPDI is a combination of data bases and analytical processes designed to assess point and nonpoint loadings to the nation's estuarine, coastal, and oceanic waters. Fifteen measures of wastewater discharge quantity and quality are included in the data base; they include flow, biochemical oxygen demand, total suspended solids, total nitrogen, total phosphorus, eight heavy metals, oil and grease, and fecal coliform bacteria. Information on permitted wastewater discharges in coastal drainages of New Jersey are contained in the data base for the Virginian Province (National Oceanic and Atmospheric Administration, 1993a). These data characterize annual and seasonal loadings during 1991 from individual discharge pipes for each permitted wastewater discharge facility. Sources of information for the data base include the USEPA's Permit Compliance System (PCS) data, paper permit files, the USEPA 's 1992 Needs Survey, typical discharge values by standard industrial code (SIC) number, and data from the U.S. Bureau of the Census.

\section{Acknowledgments}

The authors thank Isadore Cooperman and Michael Dillon of the New Jersey Department of Environmental Protection, and Steven Rubin of the U.S. Environmental Protection Agency, Region II, for supplying Permit Compliance System data retrievals and background information on the data base. 


\section{DEVELOPMENT OF A COMPUTERIZED DATA BASE OF PERMITTED WASTEWATER DISCHARGES IN NEW JERSEY}

\section{Sources of Data on Wastewater Discharges}

The statistical water-quality modeling project described by Smith and others (1989) used, to the maximum extent possible, existing computerized data bases. The data represented conditions during 1983-88, the study period chosen to be assessed by the models. The most thorough data on permitted wastewater discharges in New Jersey are available through the program that permits the release of wastewaters in the State. This program is called the New Jersey Pollutant Discharge Elimination System (NJPDES) and is similar to the National Pollutant Discharge Elimination System which regulates wastewater discharges throughout the country. Data on individual wastewatcr discharge facilities and pipes permitted under the NJPDES program are entered into the computerized national PCS data base by the New Jersey Department of Environmental Protection (NJDEP). The national PCS data base is maintained by the USEPA (U.S. Environmental Protection Agency, 1990; U.S. Environmental Protection Agency, 1991).

The PCS data base contains information provided in the application for a discharge permil, (such as facility name, address, the location of the facility producing the wastewater, the location of the discharge, the name of the receiving water, and the type of facility), the numeric discharge limitations contained in the NJPDES permit, and the results of self-monitoring by the facility on the amount and chemical quality of the discharged wastewaters. In 1990 the PCS contained data on 63,400 municipal and industrial wastewater discharges nationwide (U.S. Environmental Protection Agency, 1990). USEPA maintains other data bases that describe specific aspects of wastewater discharges, including the Industrial Facilities Discharge and Needs Survey data bases (U.S. Environmental Protection Agency, 1990). Because PCS is the only national computerized data base that contains up-to-date information on the quantity and quality of wastewaters discharged by municipal and industrial facilities together with information on permit limitations and permit compliance, PCS was chosen to be the primary data source describing wastewater discharges in the study area.

Permilted wastewater discharge data from PCS for 1986 were used rather than data for all years of the study period because the data for 1986 represent conditions in the middle of the period of study, and because PCS data were considered by New Jersey water-pollution-control officials to be more complete for 1986 than for previous years in the study period (Michael Dillon, New Jersey Department of Environmental Protection, oral commun., 1989). The 1986 PCS data were supplied by the New Jersey Department of Environmental Protection on a floppy diskette in ASCII format. An additional retrieval of 1989 PCS data in ASCII format was provided by the USEPA.

A variety of other data sources was used when the PCS data were incomplete or inaccurate. These included State of New Jersey publications, the Gianessi and Peskin (1984) data base, and paper files at the offices of the NJDEP in Trenton, New Jersey.

\section{Data-Base Development}

The permitted wastewater discharge data base was developed in two phases; the first phase was the identification and location of active permilted wastewater discharges in the study area, and the second phase was the characterization of the quantity and quality of the effluent from each discharge. (In this paper, quality of wastewater refers to either the concentration of constituents in the wastewater or the constituent load discharged during a specific time period.) Emphasis was placed on characterizing only facilities discharging process wastewaters; if a facility was found to discharge only stormwater and (or) cooling water it was removed from the data base. The procedures used to determine the locations of permilted wastewater discharges and wastewater quantity and wastewater quality are summarized in figures 2 and 3 . The information collected for a discharge is presented in table 1. 


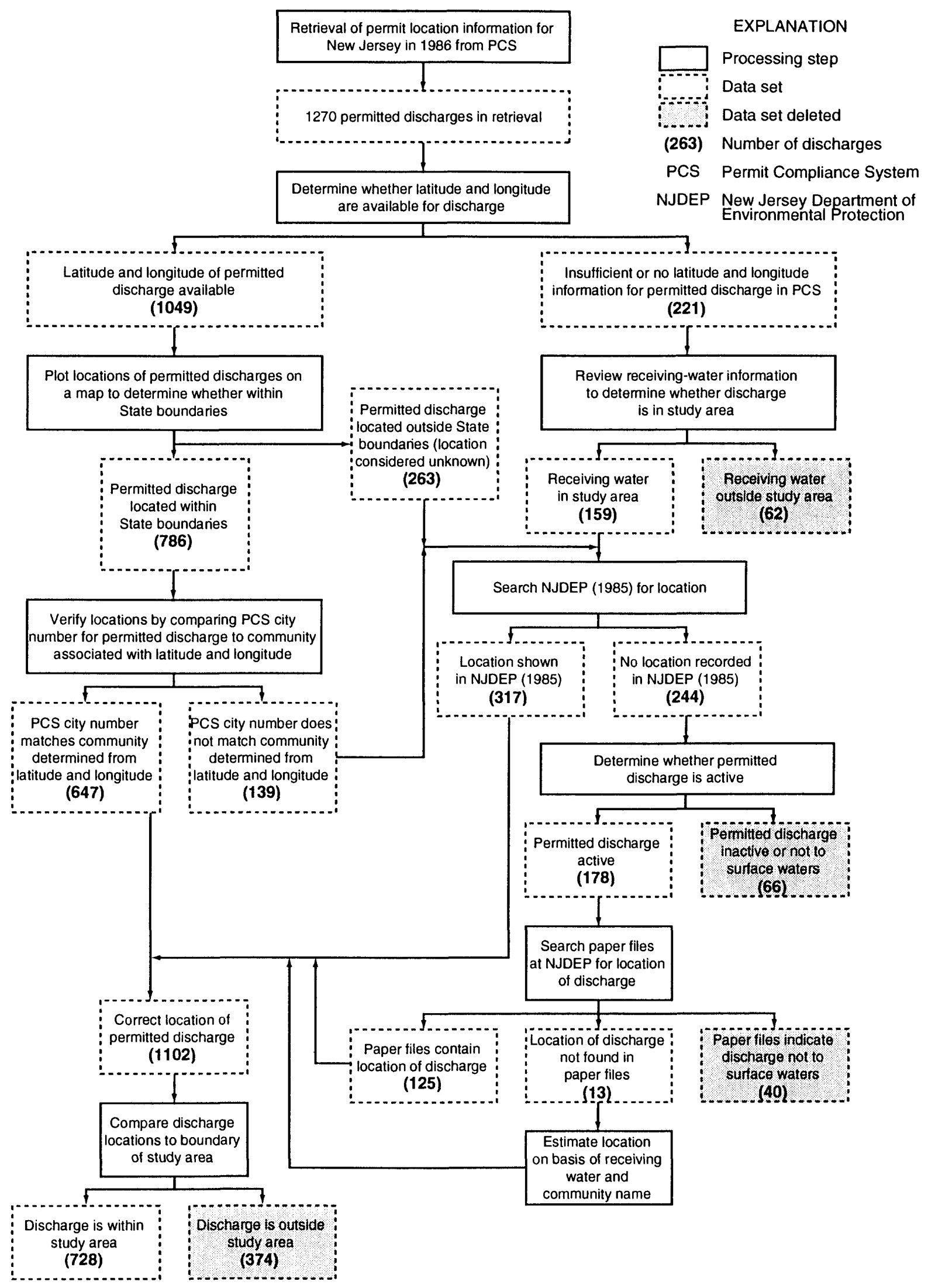

Figure 2. Methods used to determine location of permitted wastewater discharges. 


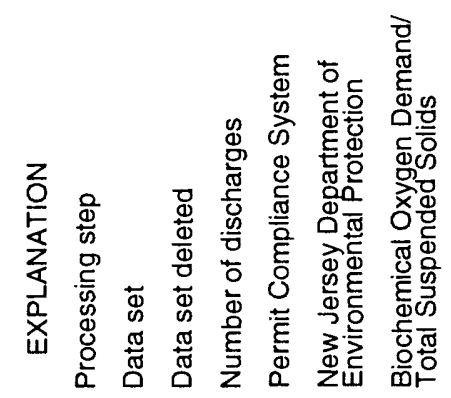

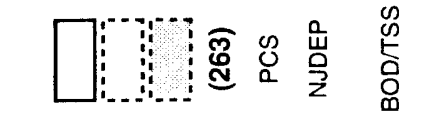

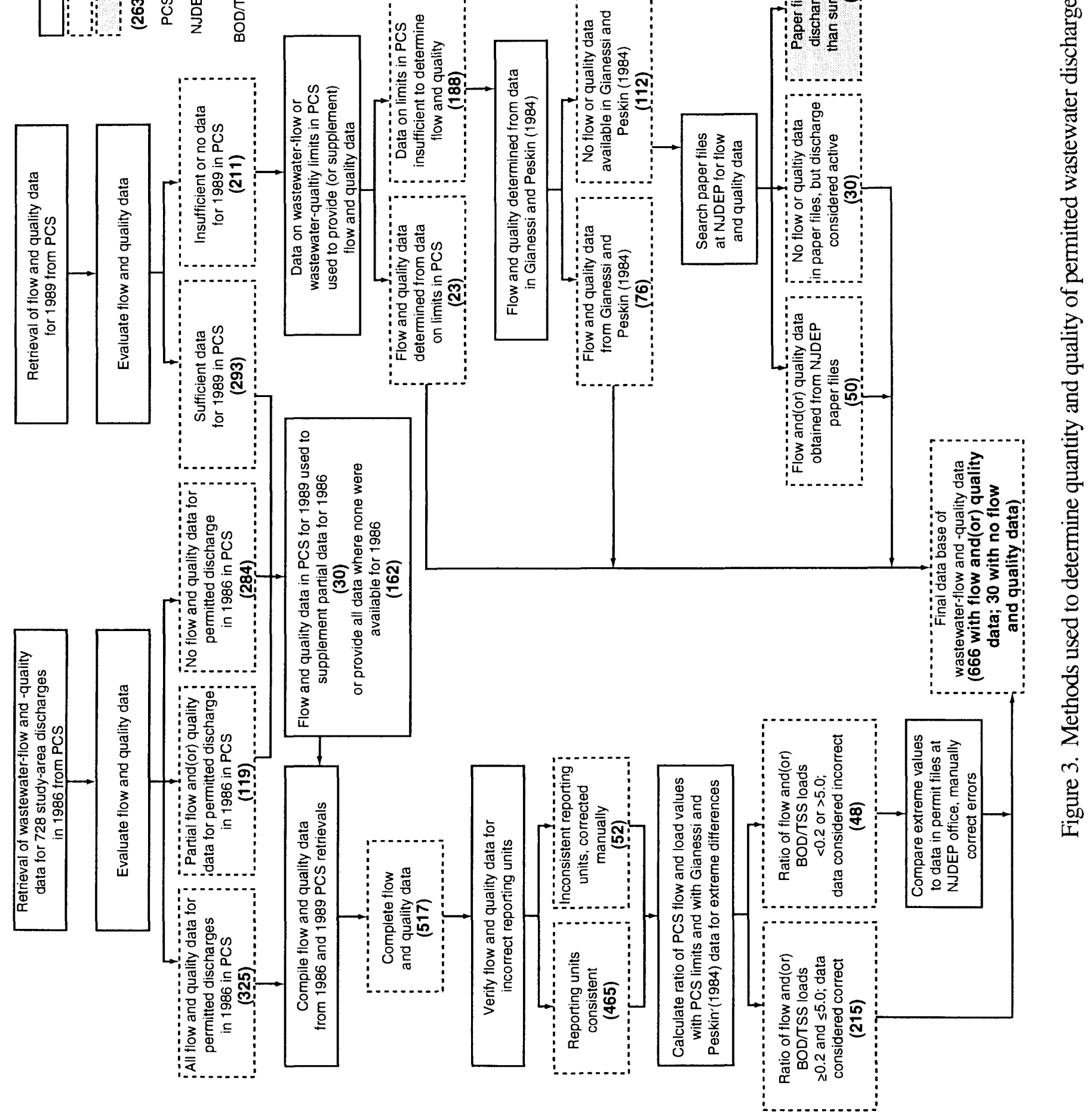


Table 1. Information collected and stored in the data base of permitted wastewater discharges

New Jersey Pollutant Discharge Elimination System permit number

Facility name

Receiving water

Latitude and longitude of facility

City and county code

Standard industrial code

Wastewater flow (million gallons per day)

Total suspended solids (kilograms per day)

5-day biochemical oxygen demand (kilograms per day)

Chemical oxygen demand (kilograms per day)

Total Kjeldahl nitrogen (kilograms per day)

Total ammonia (kilograms per day)

Total nitrate (kilograms per day) 
A vector- and point-based geographic information system (GIS) and a statistical software package were used to store and analyze all data needed for the development of the wastewater dischange data base. The GIS was used to relate spatial features to each other and to their attributes. For example, a point data set of permitted wastewater discharges can be overlaid with a polygon data set of township boundaries to determine the township location of each permitted discharge. The use of a GIS was an integral part of the data analysis required to assess the accuracy of the wastewater-discharge locations. The GIS also served as the link to the water-quality modeling process. The statistical software was used to sort, collate, and compare the various data sets collected, as well as calculate wastewater loads. Quality control checks of the data also were performed with the statistical software.

\section{Determination of the Location of Permitted Wastewater Discharges}

A retrieval of PCS data in ASCII format was supplied by the NJDEP for the 1,270 wastewater discharges in the State that were permitted in 1986. This retrieval contained general permit identification and locational information such as permit number, facility name, receiving water of the discharge, city and county codes, and latitude and longitude. The latitude and longitude value in PCS for a discharge permit was assumed to be the actual point where wastewater was discharged into a stream and, therefore, served as the primary location for the discharge in the water-quality model. (Although PCS contains a data field specifically for the latitude and longitude of the actual discharge location, these data were available for less than 10 percent of the facilities.)

The locations of the discharges in the PCS data retrieval were checked for completeness and accuracy. An initial location check was performed by comparing the discharge locations for the 1,049 facilities that had latitude and longitude data in the PCS retrieval with the boundaries of New Jersey by using the GIS. A total of 263 discharges plotted outside the State's boundaries and, therefore, were classified as having erroneous latitude and longitude data. At this point in the data-collection process, 484 discharges (38 percent of the 1,270) had either incorrect or missing latitude and longitude data; the locations of these discharges were considered to be unknown.

A verification check then was developed to assess the locational information of the 786 discharges that plotted within the boundaries of New Jersey. This verification procedure consisted of comparing the community (identified by the USEPA city number in the PCS retrieval) associated with the discharge to the municipality in which the discharge was located based on the latitude and longitude. The city number given in PCS for a discharge was assumed to be correct. The city number, which refers to the local community in which the discharge is located, is part of USEPA's Gage, City, and Dam Files (U.S. Environmental Protection Agency, 1990). The city number is unique to USEPA data bases and commonly is not spatially referenced, although some city numbers are associated with latitude and longitude data. Because of this inability to relate directly most city numbers to an exact location, a method had to be developed to relate the city numbers to existing GIS data sets that contain the locations of municipal boundaries.

This was accomplished by using the relational data-base-management capabilities of the GIS to relate USEPA's city numbers to the Geographic Names Information System (GNIS). The GNIS is a spatially referenced digital data base that contains all names found on USGS 1:24,000-scale quadrangle maps and includes latitude, longitude, feature name, and feature type (such as lake, school, municipality, or airport) (U.S. Geological Survey, 1983). A municipality from the GNIS was identified for each city number in PCS by having the GIS perform a pointin-polygon overlay of GNIS locations and New Jersey municipalities. Thus, each wastewater discharge was assigned two municipalities--one based on its latitude and longitude location and another based on the city number. These two municipalities then were compared. If the municipality assigned to a wastewater discharge on the basis of the discharge's latitude and longitude matched the municipality assigned to the city number, the discharge's location was considered to be correct. This occurred for 647 of the 786 discharges. For the remaining 139 discharges, the two municipalities did not match; the latitude and longitude of these discharges were considered to be in error and their locations unknown. The result of these data checks indicated that only 51 percent of the 1,270 discharges in New Jersey could be accurately located on the basis of the PCS latitude and longitude data. 
Of the remaining 623 discharges with inaccurate or no location information in New Jersey, 62 were manually determined to be discharges to surface waters outside the project study area (for example, the Allantic Ocean, the Delaware River, and other tidal waters) on the basis of receiving-water information in PCS. The publication Environmental Information Inventory (New Jersey Department of Environmental Protection, 1985) was reviewed to find the locations of 317 discharges; this report contains maps showing the locations of permitted wastewater discharges to surface waters in the State during 1984.

The final data source to be used for locating the remaining 244 discharges were the paper NJPDES permit application files stored at the NJDEP office in Trenton, New Jersey. These permit application files frequently contain a map showing where the discharge facility is located. Prior to reviewing the paper files a determination was made of whether the discharge was active or inactive. This was done to minimize the time required to search the paper files. A discharge was considered active if it was listed in a State publication that identifies all permittees assessed a fee to discharge in 1988 (New Jersey Department of Environmental Protection, 1988) (no similar publication was available for 1986), or if PCS contained Discharge Monitoring Report (DMR) data on the quantity and quality of wastewaters discharged during 1986 or 1989 . This process identified 66 of the unlocated discharges as being inactive, a ground-water discharge, or a stormwater discharge; these discharges then were deleted from the data base. If the unlocated discharge was found to be active, information on its location was obtained from the paper permit application files. The location of 125 discharges were determined in this manner. In addition, information in the paper permit application files indicated that 40 of the unlocated discharges were either inactive or a ground-water discharge; these 40 facilities also were deleted from the data base. Finally, the locations of 13 active discharges had to be manually estimated because the paper files contained no locational information. The estimation was based on the receiving water of the discharge and any address information for the facility that could be found in the paper files.

The final step in the process of locating permitted wastewater discharges within the study area was to overlay the 1,102 located discharges with the study area boundaries. This identified 728 permitted wastewater discharges within the study area.

\section{Determination of the Quantity and Quality of Permitted Wastewater Discharges}

A retrieval of PCS data in ASCII format on the quantity (flow) and quality (constituent concentration or load) of wastewaters discharged in 1986 for permitled discharges in New Jersey was provided by the NJDEP. These data were derived from information contained in the DMR's submitted to the NJDEP. An additional retrieval of DMR and permit limitations data for 1989 in PCS was needed to fill gaps in the data for 1986.

The DMR data in PCS is based on the specific reporting requirements for each discharge facility; for facilities with more than one discharge pipe, these reporting requirements usually vary from discharge pipe to discharge pipe. The DMR data are most often reported as the average wastewater quantity and quality discharged for a reporting period, although some facilities report only the minimum and or maximum amounts discharged. Depending on the facility, reporting periods for a DMR range from monthly to yearly. The quantity of wastewater discharged is expressed in PCS as either million gallons per day or gallons per day. Reported data on the quality of wastewaters varies greatly depending on the facility type, but tend to be described most frequently in terms of 5-day biochemical oxygen demand (BOD), chemical oxygen demand (COD), and total suspended solids (TSS). Other measures of wastewater quality, such as nutrients (nitrogen and phosphorus compounds) and trace elements, were reported with PCS with much less frequency; for example, the amount of total ammonia discharged was reported for only 15 percent of the discharges in the study area. Because BOD, COD, and TSS data were reported by facilities at a much greater frequency than other water-quality constituents, a decision was made for the investigators early in the data collection process to focus on these measures, although nitrogen data were collected and stored in the data base when the data were available. No attempt was made by the investigators to estimate loads of these constituents on the basis of facility type and size when no data could be found for a discharge. The DMR data in PCS for most water-quality constituents are presented as a load (for example, kilograms per day), and (or) as a concentration (commonly 
expressed in milligrams per liter). For application in the water-quality model, all wastewater quality data collected were stored in the data base as a load in units of kilograms per day.

The median flow and constituent load and (or) concentration for each discharge pipe were determined from the DMR data. A median value, rather than a mean, was calculated because of concerns over data variability from one reporting period to the next. The median value was assumed by the investigators to be a better indicator of the central tendency of the flows or loads than the mean value because it is affected less by extreme outliers in the data. The median values were not intended to be representative of the true median value for a year, however, but rather to serve as a better central measure of the DMR values reported.

Constituent-load data, when available in PCS, were used directly; when load data were not available, loads were calculated from concentration and flow data. Median loads were calculated from the median wastewater flow and median constituent concentrations reported in PCS. If only minimum and maximum values were reported, the average of the median minimum and maximum values were used. If only minimum or maximum values were reported, the median of these values were used. When a permitted discharge included more than one discharge pipe, flows and constituent loads for each pipe were determined individually and then added to determine the total flow and loads for the permitted discharge.

Wastewater quantity and quality data derived from 1986 DMR's in PCS were considered to be optimal because they were for the middle of the study period and corresponded to the time period of the location information. However, data on only 444, or 61 percent, of the 728 discharges in the study area were contained in the retrieval from PCS of wastewater-quantity and -quality data for 1986. Results of additional analysis of these data showed that sufficient data were available to determine wastewater flows and (or) constituent loads for only 325 of the 728 discharges. These 325 permitted discharges had a total of 421 individual wastewater-discharge pipes.

PCS data derived from 1989 DMR's were used to fill gaps in the 1986 PCS data because the 1989 data were considered to be the most reliable and complete at the time of data base development (the 1989 data were assumed to be representative of 1986 conditions). Subsequently, the quantity and quality of 162 additional wastewater discharges (203 discharge pipes) were characterized with the 1989 DMR data. Wastewaters associated with 30 discharges were characterized with data from PCS for 1986 and 1989 combined. In total, DMR data from PCS for 1986 and 1989 provided wastewater flows and (or) constituent loads for a total of 517 permitted wastewater discharges (71 percent of the 728 permitted discharges in the study area). The 1986 and 1989 PCS data contained only constituent concentration data for another 129 discharges. These data were without flow data and, therefore, were insufficient to determine the loads of a constituent discharged.

If PCS contained no DMR data, or only constituent concentration data, for either 1986 or 1989 , the missing data were derived from other sources. Permit limits data in PCS for 1989 were sufficient to estimate wastewater flows and (or) loads for 23 discharges. Data from the Gianessi and Peskin (1984) study provided information on another 76 discharges. Finally, paper permit files containing DMR's and permit application information at the NJDEP office in Trenton, New Jersey, were used to obtain data on wastewater quantity and quality for 50 discharges with no or partial wastewater data. For certain discharges, data from two or more of these sources were needed to estimate the quantity and quality of wastewater.

During the review of paper permit files, 32 discharges were found to be a pretreatment facility or a discharge to ground waters. These 32 discharges were eliminated from the data base, resulting in a final count of 696 discharges in the data base (fig. 4). No wastewater-quantity or -quality data could be found in any source for 30 (4 percent of the total) of the 696 permitted discharges, although the NJDEP considered them to be actively discharging in 1988 (New Jersey Department of Environmental Protection, 1988). No additional attempts were made to characterize the wastewaters of these facilities because they were perceived by the investigators to be minor discharges. A measure of wastewater flow was collected for 644 of the 696 discharges in the data base. TSS data were collected 


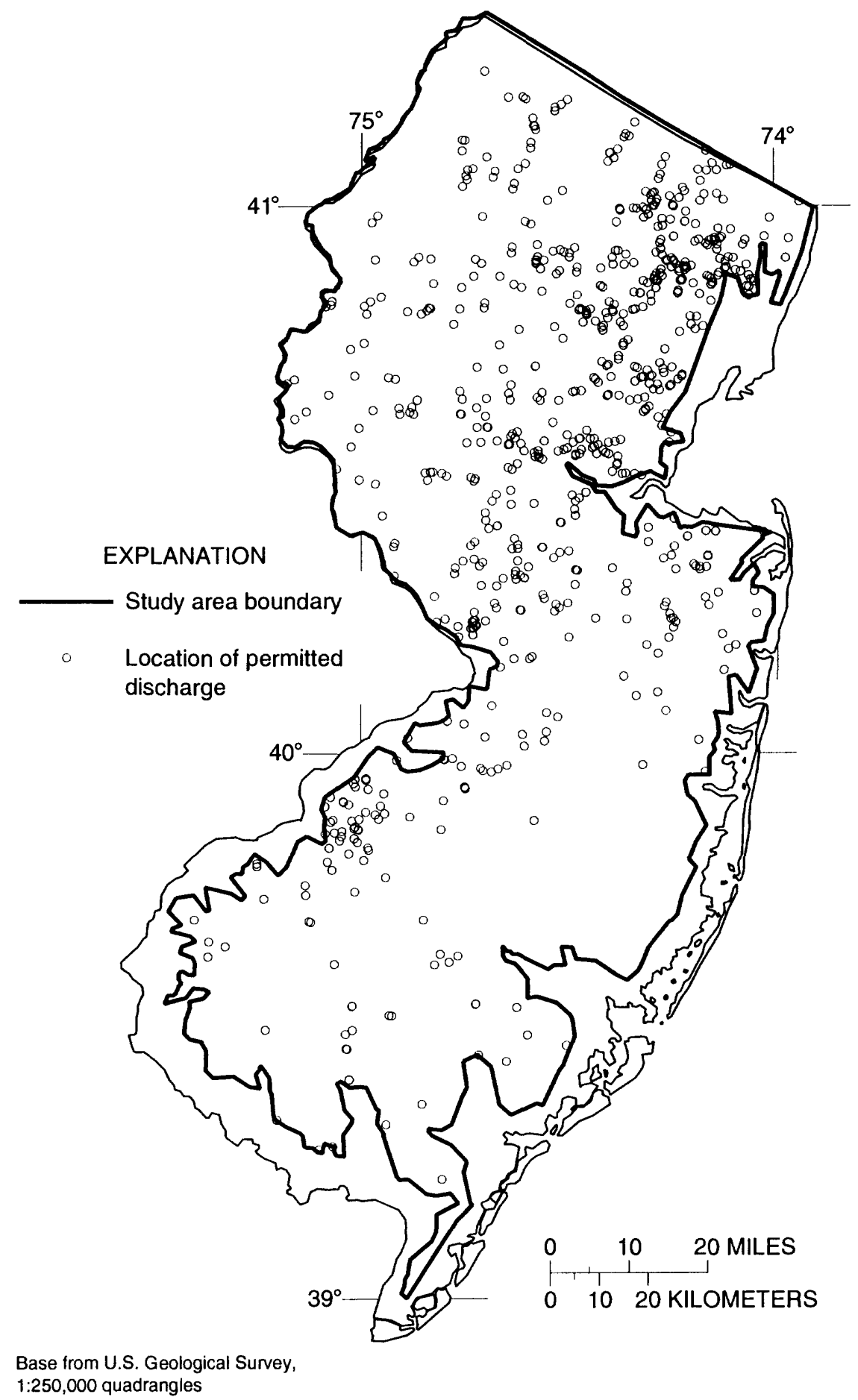

Figure 4. Locations of the 696 permitted wastewater discharges to surface waters in the study area. 
for 634 discharges, BOD data for 365 discharges, and COD data for 320 discharges. The most frequently measured form of nitrogen was total Kjeldahl nitrogen, which was reported for 117 facilities. A facility's SIC code was identified for 96 percent of the 696 discharges.

Quality-control procedures were used throughout the compilation of the wastewater-quantity and -quality data. Prior to calculating a load from concentration and flow data, these data were manually checked to ensure that the reporting units were consistent. Of 535 permitted discharges for which PCS contained data on the amount of wastewater discharged, 40 discharges (7 percent) reported flows in gallons per day or in both gallons per day and million gallons per day, despite the discharge-permit requirements to report flows in million gallons per day. A less frequent problem with the data in PCS was the inconsistency of units used for reporting constituent loads-for example, loads of a constituent for a discharge were reported in grams per day in the actual DMR, whereas the loads were reported in kilograms per day in PCS. When such discrepancies were found, they were corrected manually before median loads were calculated.

A second quality control check was developed to assist in identifying discharges for which the data in PCS might be in error. Ratios of the wastewater-flow and -constituent load data derived from the 1986 and or 1989 PCS DMR data to the 1989 permit limits data in PCS or to the data in Gianessi and Peskin (1984) (termed the "load ratio") were generated. A load ratio less than 0.2 or greater than 5.0 was used to flag possible inaccuracies in PCS load data. Of the 263 discharges involved in this comparison, load ratios for 48 discharges exceeded these values. The cause for 67 percent of these flagged values was that the PCS loads for 1986 or 1989 were substantially lower than those reported in Gianessi and Peskin (1984). To verify these differences, paper files containing the original 1986 and 1989 DMR's for the 48 permits were reviewed. Results of this review showed that all load ratios of 5.0 or greater were the result of data-entry errors or the use of incorrect reporting units; all load ratios less than 0.2 represented actual wastewater quantity and (or) quality. When needed, corrections to the data base were made manually.

\section{SUMMARY}

A computerized data base containing information on the locations of permitted wastewater discharges to nontidal surface waters in New Jersey during 1986 and the quantity and quality of the wastewaters discharged was developed for use in a water-quality modeling project. The primary source of information on the wastewater discharges was U.S. Environmental Protection Agency's national Permit Compliance System (PCS) data base. The PCS data base contains data supplied by permittees in their application for a wastewater discharge permit, the numeric limitations of a discharge permit, and the results of self-monitoring by the permittee. Because data for many wastewater discharges were missing or were incorrect in the PCS data base for the year 1986, a retrieval of 1989 PCS data, a second national data base, other published data, and paper files at the office of New Jersey Department of Environmental Protection were used. In addition, several quality-control checks were conducted because of concerns regarding the accuracy of the location and wastewater-quantity and -quality information in PCS.

Location information (latitudes and longitudes) were considered correct in PCS for 51 percent of the 1,270 permitted wastewater discharges in New Jersey in 1986. Even after quality-control steps were taken to compare the latitude and longitude data in PCS to other location information for a discharge, the accuracy of the discharge location could not be determined. Other sources of location information included a State of New Jersey report that showed discharge locations and paper files at the offices of the New Jersey Department of Environmental Protection. The locations of 13 discharges were estimated because no location information could be found in any source.

Data retrieved from PCS for years 1986 and 1989 were sufficient to characterize the amount of wastewater flow and (or) loads of total suspended solids, biological chemical demand, and chemical oxygen demand discharged for 74 percent of the 696 permitted wastewater discharges used in the water-quality model. Data on the amount of nitrogen discharged were available for less than 20 percent of the permitted discharges. No wastewater-quantity or -quality data were available for 4 percent of the discharges, even after the data obtained from PCS were 
supplemented with data obtained from other sources. Most of the wastewater-quality data in PCS accurately reflected the information submitted by the permittee in the DMR's; however, errors resulting from the incorrect reporting of units of measure were found in the flow data for 7 percent of the facilities. State publications, an additional national data base from the early 1980's, and paper permit files were used to supplement the PCS data.

As much as 30 to 50 percent of the information on permitted wastewater discharges needed as input data for the water-quality model was not in PCS; therefore, this data base alone was insufficient as a data source. In addition, errors found in PCS data fields ranged from 5 to 25 percent, necessitating the checking of all data prior to use. 


\section{REFERENCES CITED}

Association of State and Interstate Water Pollution Control Administrators, 1984, America's clean water--The state's evaluation of progress 1972-1982: Washington, D.C., 16 p.

Gianessi, L.P., and Peskin, H.M., 1984, An overview of the RFF environmental data inventory: Methods, sources and preliminary results, volume 1, Resources for the Future: Washington, D.C., 111 p.

Luken, R. A., Basta, D. J., and Pechan, E. H., 1976, The national residuals discharge inventory: National Research Council, Washington, D.C., 231 p.

National Oceanic and Atmospheric Administration, 1993a, Point source methods document for the Virginian Province -the national coastal pollutant discharge inventory: Silver Spring, Maryland, Pollution Sources Characterization Branch, variously paginated.

1993b, Point source methods document - the national coastal pollutant discharge inventory: Silver Spring, Maryland, Pollution Sources Characterization Branch, variously paginated.

New Jersey Department of Environmental Protection, 1985, Environmental information inventory: Trenton, New Jersey, variously paginated.

New Jersey Department of Environmental Protection,1988, New Jersey pollutant discharge elimination system--1988-1989 annual fee report and assessment of fees: Trenton, New Jersey, 139 p.

New Jersey Department of Environmental Protection, 1990, New Jersey 1990 state water quality inventory report: Trenton, New Jersey, 360 p.

Smith, R.A., Alexander, R.B., Robinson, K.W., Price, C.V., White, D.A., Lins, K.F., and Jenson, S.K., 1989, Application of geographic information systems to statewide water-quality assessment, in Second National Symposium on Water Quality: Abstracts of the Technical Sessions, Orlando, Florida, November 12-17, 1989: U.S.

Geological Survey Open-File Report 89-409, p. 92.

U.S. Environmental Protection Agency, 1987, National water quality inventory--1986 report to Congress, Rep. EPA-440/4-87-008: Washington, D.C., 141 p.

1990, Office of water environmental and program information systems compendium--FY 1990, Rep. 500/9-90-002: Washington, D.C., 125 p.

1991, Permit compliance system codes and descriptions manual, Doc. PCS-CD91-1.01, PCS Users Support: Washington, D.C., variously paginated.

U.S. Geological Survey, 1983, The national gazetteer of the United States of America--New Jersey: U.S. Geological Survey Professional Paper 1200-NJ, Washington, D.C.

Zogorski, J.S., Blanchard, S.F., Romack, R.D., and Fitzpatrick, F.A., 1990, Availability and suitability of municipal wastewater information for use in a national water-quality assessment: a case study of the Upper Illinois River basin in Illinois, Indiana, and Wisconsin: U.S. Geological Survey Open-File Report 90-375, 68 p. 